\title{
Percepção de saúde na etnia Guarani M byá e a atenção à saúde
}

\author{
Perception of health among the Guarany M byá ethnic group \\ and health care
}

Almir de Amorim Von Held ${ }^{1}$

$M$ arianna Soares Chaves Lopes ${ }^{1}$

Sônia M aria N eves Bittencourt de Sá ${ }^{1}$

Dora de Oliveira e Silva Porto ${ }^{1}$

${ }^{1}$ CátedraUNESCO de Bioética, Faculdadede Ciências da Saúde,

Universidade de Brasília. Caixa Postal 04451. 70904-970 Brasília DF. bioetica@unb.br
Abstract The article results from a qualitative research on the perception of health of the Guarany $M$ byá ethnic group held in 3 villages in the South of Brazil. The cultural characteristics of the group were surveyed in the literature, observed in fieldwork and confirmed in the 20 open interviews conducted with community members and health professionals from the $\mathrm{N}$ ational Health Foundation (FUNASA), responsible for the basic assistance to the villages. The results show that the $M$ byá consider the cultural shock with the surrounding society the main factor of illness, emphasizing the importance of preserving and enhancing their traditional way of living for maintaining the health of individuals and communities. The data allow to associate their health representations to the land and social justice problems experienced by the groups. They point to the importance of improving the training of the technical health staff, specifically related to the understanding of the inter-ethnic differences between the $M$ byá and Western culture to ensure the effectiveness of treatments and programs. Theanalyses also highlights positive and negative aspects of the operationalization of health care in the villages and in the final considerations are given suggestions aiming its improvement.

Key words Health, Bioethics, M oral strangers, Inter-ethnic contact, Guarany M byá ethnic group
Resumo 0 artigo resulta de pesquisa qualitativa sobrea percepção desaúde da etnia Guarani M byá, realizada em três aldeias no Rio Grande do Sul e uma em Santa Catarina. As características culturais da etnia foram pesquisadas na literatura, observadas no trabal ho de campo e confirmadas nas vinte entrevistas abertas realizadas com membros das comunidades e profi ssionais de saúde da Fundação Nacional de Saúde (Funasa) que responde pela assistência básica às aldeias. Os resultados mostram que os $\mathrm{M}$ byá consideram o choque cultural com a sociedade envolvente o principal fator deadoecimento, enfatizando a importância depreservar e valorizar seu modo de vida tradicional para a manutenção da saúde de indivíduos e coletividades. Os dados permitem associar suas representações sobre saúde aos problemas fundiários e de justiça social vivenciados pelos grupos. A pontam a importância de aprimorar a formação dos quadros técnicos de saúde, especificamente no que diz respeito à compreensão das diferenças interétnicas entre a cultura M byá e ocidental para garantir a efetividadedetratamentoseprogramas. A análise ressalta ainda aspectos positivos e negativos na operacionalização da assistência à saúde nas aldeias e, nas considerações finais, são apre sentadas sugestões para seu aprimoramento.

Palavras-chave Saúde, Bioética, Estranhos morais, Contato interétnico, etnia Guarani M byá 
Quem são os Guarani M byá

A população indígena brasileira é estimada em mais de quinhentas mil pessoas, pertencentes a 230 povos com 180 línguas. Dentre estes, acredita-se que os Guarani M byá sejam entre seis mil e novemil indivíduos, quefalam alíngua Guarani, do tronco Tupi.

A nação Guarani habita áreas do Paraguai e N ordesteda Argentina. Diferenças dial etais eculturais estabeleceram três denominações para a etnia: Kaiowá, N handeva e M byá. No Brasil, os N handeva e os M byá vivem em aldeias no litoral, concentrando-se nos estados do Sul e Sudeste, e os Kaiowá, em áreas do M ato Grosso do Sul.

A pesar de não se verem como nômades nem seminômades, seusmovimentos migratórios vêm sendo registrados ao longo da história. A mobilidade espacial reflete sua concepção de mundo, na qual a noção de território está baseada nas dinâmicas sociais, econômicas, políticas entre as aldeias (tekoa), englobando ainda as rel ações com outros grupos étnicos ${ }^{1}$. Esse processo de contato constante entre pessoas de tekoa diferentes é 0 que delimita a noção de território, entendido como espaço onde se dão as relações da comunidade. As razões para o deslocamento entre os tekoa incluem visitas a parentes, encontros para realizações de rituais, bem como trocas de maté rias-primas para artesanato e cultivo. Dada essa dinâmica, édifícil definir com precisão a quantidade de pessoas em cada tekoa, que pode variar entre quarenta e poucas a centenas de indivíduOS. Q uanto à localização, os grupos menorestendem a estar perto dos centros urbanos e ao longo de rodovias e os maiores, no interior, preferencialmente junto à mata.

Esse constante deslocamento ou caminhadas (guata) obedece muitas vezes a razões de ordem prática, mas tem também importante função ritual, reconstruindo no cotidiano a cosmogonia e renovando a memória do mito da fundação do mundo e de seus heróis, personificados pelos líderes xamânicos: A caminhada da comunidade, unida pela solidariedade e as alianças familiares, institui o mundo M byá, nomeando- 0.0 caminhar simboliza a trajetória da existência coletiva e individual na construção do mundo terreno, o processo contínuo de realização do destino do indivíduo eda sociedade 2 . Guimarães ressalta quea vida social em uma aldeia M byá está totalmente entrelaçada com os diver sos planos e regiões do Cosmo. Talvez fosse melhor dizer que a vida desta etnia neste mundo depende das rotas que ligam às dimensões do Cosmo ${ }^{3}$.
A primeira condição para consubstanciar essa cosmogonia fundante dos $M$ byá é a de que os tekoa estejam localizados em áreas com recursos naturais preservados, permitindo a privacidade da comunidade e o manejo de espécies tradicionais destinadas a garantir a subsistência'. Essa proximidade da mata, fundamental para a manutenção da dinâmica social, religiosa e econômica do tekoa, condiciona a sobrevivência da comunidade, tanto efetivamente quanto na dimensão simbólica: Esses lugares, procurados ainda hojepel os $M$ byá, apresentam elementos da flora e da fauna típicos da M ata Atlântica, formações rochosas e mesmo ruínas de edificações antigas, indícios que confirmam a tradição. Formar aldeias nesses lugares "eleitos" significa estar mais perto do mundo celestial, pois, para muitos, é a partir desses locais que 0 acesso a Yvy M arãey, "Terra sem M al", é facilitado - objetivo histórico perpetuado pel os $M$ byá através de seus mitos ${ }^{1}$.

Essa relação entre a dimensão sagrada e o mundo, manifesta na importância das matas, florestas, rios e das espécies da flora efauna, estende-se também às terras destinadas ao cultivo, às quais também são presente de $\mathrm{N}$ handeru (Deus), fazendo parte da cosmogonia que orienta as noções estruturais eas relações com o mundo. Disse um entrevistado, indígena residente na Terra Indígena Lomba do Pinheiro (RS): “O que os Guarani não podem perder para manter a saúde? A terra". Dentre as espécies cultivadas, destaca-se o milho indígena, avati, base da alimentação tradicional, considerado sagrado por ter sido presente de N handeru. Compõe também sua agricultura de subsistência o cultivo da mandioca (mandió eté), batata-doce (jety), frutas, chá-mate (ka á), melancia, abóbora, cana, amendoim (manduvi).

Dadas as características desse modo de produção, sua dieta é baseada na coleta, na pesca e caça, bem como no consumo de cereais, raízes e leguminosas cultivados. Segundo eles, esses alimentos mantêm a pessoa saudável e equilibram o corpo. Almeida menciona ainda que "as casas Guarani têm sempreao redor do pátio verdadeiras farmácias de pohã ñana (ervas)" 4 . As pessoas que possuem o conhecimento sobreo uso desses remédios são chamadas mba'y e kua'a.

A organização espacial dos tekoa também re produz as crenças $M$ byá, sendo essencial à construção das identidades eà reprodução de modos de vida e comportamento que instauram a noção de pertencimento. Pela tradição, a casa de oração, opy, deve ser o centro de referência do tekoa. Todas as aldeias possuem opy, na qual os karaí (rezadores) identificam o tipo de doença 
do indivíduo: as práticas religiosas dos M byá são frequentes e se estendem por muitas horas. O rientadas pelo dirigente espiritual as "rezas" - realizadas através de cantos, danças e discursos - também se voltam às situações e necessidades corriqueiras (colheita, ausência ou excesso de chuva, problemas familiares, acontecimentos importantes, imprevistos) ${ }^{1}$.

Quanto à organização social, as famílias são, em geral, extensas, compostas pelo casal, filhas, genros e netos, constituindo uma unidade de produção e consumo: a "propriedade" das roçase o consumo dos produtos é da família elementar, depois do nascimento dos filhos do casal [...] o que não exclui os serviços nas roças do sogro e a realização de mutirões entre as famílias'. São avessos ao conceito de posse como propriedade individual e as decisões são tomadas na coletividade, pela consulta a parentes (vivos e mortos).

Normalmente os idosos, tamõi (classificação genérica próxima ao sentido de avô), são considerados consel heiros. Sendo os que mais conhecem o mundo espiritual, tornam-se guias dos jovens: "os idosos são as raízes, pois eles têm a sabedoria", segundo mencionou o indigenista Witt ${ }^{5}$. A importância da sabedoria desses tamõi para a dinâmica social pode ser inferida na forma como percebem eagem no cotidiano: Para os M byá o cotidiano está impregnado de relações míticas, advindas da comunicação com as divindades. Assim, astradições são postas em prática secularmente, segundo os princípios dos mitos quefundamentam o pensamento e ações dos M byá 1 .

A organização temporal também reflete a dinâmica coletiva. Diferente dos juruá (brancos), o tempo não é função da produtividade ou ordenado por padrões fixos de organização do trabalho. Tudo ocorre conforme a necessidade, já que não há na tradição a ideia de progresso a perseguir, nem de acumulação exaustiva de bens materiais.

Os M byá buscam fortemente manter seu ethos, construído em torno de quatro princípios: obedecer a N handeru; serem guardiões das florestas; serem seres em liberdade e buscarem a "Terra sem Mal", Yvy M arãey. Esses princípios condicionam a nhande rekó (algo como "nossa forma de ser Guarani"). Assim, o bom Guarani é aquele que vive de acordo com a tradição, por meio da qual pode atingir o aguyje, um estado de elevação espiritual que ajuda a deixar a "terra imperfeita" e alcançar a Yvy M arãey.

Como acreditam que são seres em liberdade, buscam evitar o confronto; exercem sua autonomia por uma aparente não resistência, anco- rada na convicção de não aderir às práticas e valores que se contraponham às noções comunitárias. 0 sentido de liberdade e autonomia manifesta-se na defesa de modos de vida que reafirmam a nhande rekó. Algumas comunidades rejeitam a educação juruá e afirmam que já possuem a sua, sistematizada na aprendizagem da dinâmica coletiva cotidiana da próprianhanderekó, e que a prática da primeira, muitas vezes, prejudica a segunda: "a nossa escola é o joguinho, a oração, o chimarrão as histórias, dentro da nossa experiência vivida. A gente sabe dentro do nosso opy quando plantar o milho sagrado", segundo um indígena entrevistado, também residentena Terra Indígena Lomba do Pinheiro (RS).

Com relação à saúde, exercem sua autonomia frente à moralidade juruá, mantendo suas opiniões e visões de mundo. Se lhes são impostos valores ou razões que não compartilham, simplesmente não aderem às políticas, programas ou tratamentos de saúde. Quando se manifesta a condição que identificam como doença, procuram o karaí na opy; só buscam a medicina juruá se comprovado que se trata de doença de branco. Adotam a terapêutica tradicional, baseada em regimealimentar einterdições, no uso de leite materno, gordura e cinzas de animais ou plantas, preparados como chás eunguentos, aplicados em fricções4.

A maneira como concebem e vivenciam a relação saúde/doença também está associada à espiritualidade è cosmologia. Para eles, a doença pode surgir na pessoa porque a sociedade está doente. Então, para falar da doença, é preciso deslocar o problema do indivíduo para o coletivo, nos tipos de relações que se estabelecem na sociedade, na natureza e no sobrenatural. $\mathrm{Na}$ anamnese, 0 karaí pergunta sobre eventuais traumas, sonhos, pesadelos e sustos do paciente (e de seus parentes) para, enfim, prescrever o tratamento. Assim, transcende a dimensão física do paciente para produzir o diagnóstico.

Por serem historicamenteágrafos e seguirem a tradição oral, valorizam bastante as palavras. As boas palavras e os cantos são extremamente importantes para viver deacordo com a nhanderekó, pois, inspiradas espiritualmente, têm poder deorientar. Para os M byá, falar se confunde com o próprio ser: o nomeéa pessoa, reconhecida pela entonação da voz e pela cadência da fala. N essecontexto, somente os que falam o idioma são considerados membros da tribo, sinalizando queo pertencimento é definido pelo domínio da palavra.

Essa breve descrição da vida social e visão de mundo dos M byá mostraquea nhande rekó pode 
ser associada à vida boa ou felicidade, segundo a definição grega, ou à qualidade devida, na classificação atual. N esse contexto, a saúde deriva da manutenção do modo de vida tradicional, associada aos fatores objetivos, do ambiente natural e social, e condicionada àqueles relacionados à dinâmica da comunidade, à obediência à nhande rekó. Para esse povo, viver segundo "o nosso jeito de ser Guarani", ou seja, garantir este ethos, éa razão de sua resistência à aculturação, o queimplicitamente se traduz em saúde.

\section{M étodo}

Decunho qualitativo, o trabal ho de campo contou com dezesseteentrevistas em três comunidadesindígenas do Rio Grande do Sul (RS) euma em Santa Catarina (SC) em novembro de2007 (Figura 1). No primeiro estado, foram visitadasaAldeiaLomba do Pinheiro, na periferia da capital, onde foram feitas três entrevistas; a Aldeia deInhakapetum, no Município de São Miguel das Missões; e a Aldeia Pacheca, Município de Camaquã, nas quais foram feitas cinco entrevistas cada. Foram entrevistadas também quatro pessoas na Aldeia Araçaí, em Santa Catarina. Em todas as localidades, foram entrevistados o cacique, profissionais da Fundação $\mathrm{Na}$ cional de Saúde - Funasa (enfermeiros, técnicose auxiliares) e os agentes de saúde indígenas (AIS), membros da aldeia, capacitados para assistência. Também foram feitas mais três entrevistas com enfermeira do Pólo Base da Funasa em Chapecó (SC), com antropóloga da Fundação Nacional do Índio (Funai) em Braślia e com indigenista da Funai/RS, totalizando vinte depoimentos.

A técnica foi a entrevista aberta, a partir de roteiro semi-estruturado focado na representação de saúde da etnia M byá. Procurou-se levantar como se dá a relação entrea Funasa e os M byá e se consideram que há respeito a suas tradições no que concerne ao tratamento.

Foram feitas duas visitas a cada aldeia, intermediadas pelo indigenista W itt, queacompanhou a equipe no Rio Grande do Sul; a primeira para apresentação e explicação da pesquisa e do termo de consentimento livre eesclarecido (TCLE) e a segunda para as entrevistas, tomadas coletivamente. D evido à vulnerabilidade dos entrevistados, neste artigo, as falas não foram identifica-

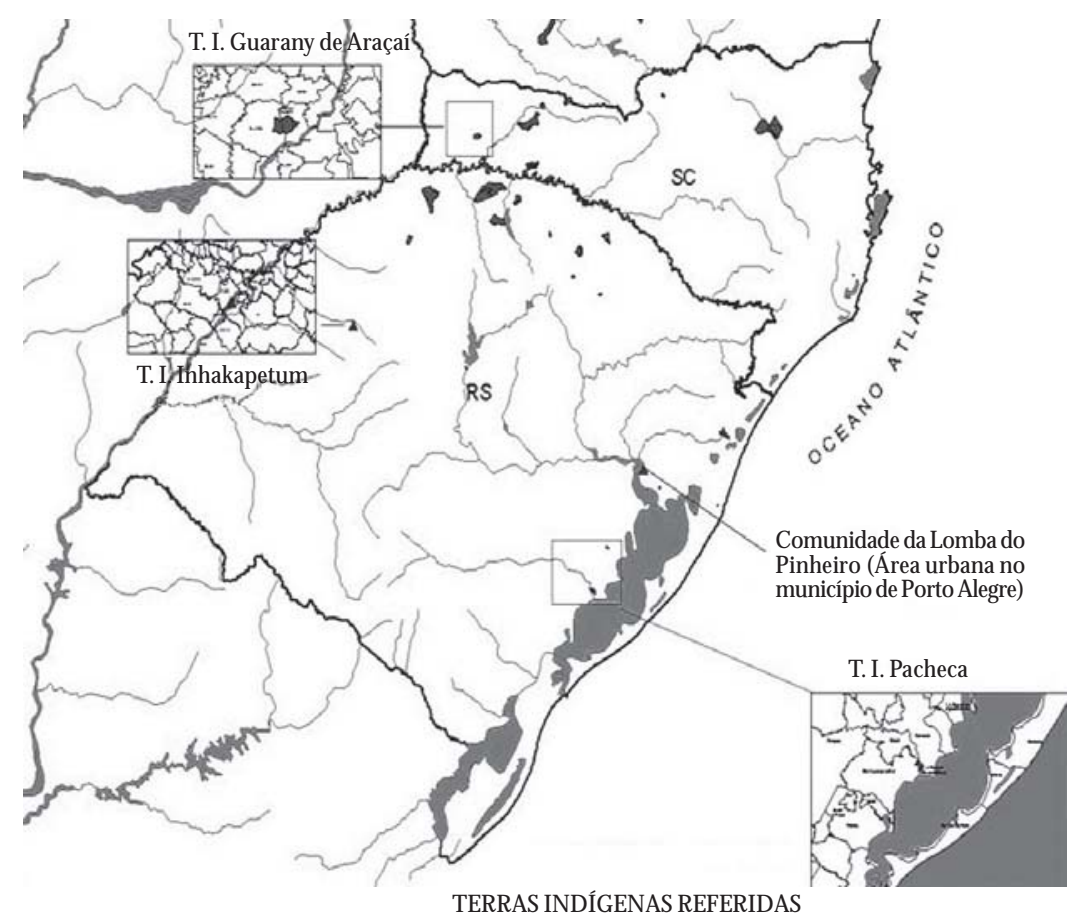

Figura 1. Localização das Terras Indígenas Inhakapetum, Pacheca e Lomba do Pinheiro (RS) e Araçaí (SC). 
das para garantir o anonimato, já que o material foi tomado em um número restrito de localidades. Os depoimentos foram escritos e lidos para que os entrevistados validassem-nos. A pesquisa foi aprovada pelo Comitê de Ética da Universidade de Brasília.

\section{Resultados}

\section{Terra Indígena Guarani da Pacheca}

Localizada a 160 quilômetros de Porto Ale gre, em Camaquã, a aldeia situa-se em área afastada três quilômetros da vila mais próxima. Conta com aproximadamente oitenta indígenas. Está cercada de matas nativas e pelo Rio Camaquã, o que favorece a preservação da cultura e da forma de ser Guarani.

No roçado de subsistência, cultivam os alimentos que consi deram básicos, inclusive o avati sagrado. As casas, feitas por eles, localizam-se em posições que resguardam as famílias. $\mathrm{N}$ ão há luz por decisão comunitária, com o que alguns não concordam. Também não há água tratada. A água é retirada do rio, a trezentos metros da aldeia. A maioria domina a farmacologia natural e cultivam pohã ñana (ervas medicinais) e as mulheres fazem seus partos.

Foi possível observar forte coesão da comunidade. Os mais vel hos continuam a ser os guardiões da sabedoria e da tradição de cura. O AIS respeita a hierarquia tribal bem como a tradição da opy, sempre consultada em primei ro lugar no atendimento. Foi relatado bom entrosamento entre Funasa e Funai.

A crença na "Terra sem M al" é vista pelo grupo como fundamental para manter o ethos Guarani e o constante aperfeiçoamento espiritual. 0 conceito de saúde envolve a harmonia entre corpo, alimento erelação social. A al egria favorecea saúde e esta pode ser obti da pelo cultivo de uma boa terra e a presença da mata, que permite a obediência à vontade de N handeru. Para esta comunidade, a guata é forma de aperfeiçoar a espiritualidade, promover a saúde e garantir o bemestar coletivo. Para eles, a doença pode ser provocada pela poluição, trazida pelo ar e pela falta de harmonia no grupo.

Embora na aldeia não exista posto da Funasa, a comunidade é atendida pelo menos uma vez por semana por enfermeiros na casa da cultura do índio. O AIS confirmou que a Funasa promove cursos de formação em vacinação, acompanhamento do desenvolvimento infantil (normalmente por processos biométricos), primeiros socorros e diferentes tipos de atenção aos idosos. São os AIS que intermedeiam 0 atendimento entre a aldeia e os centros de atendimento. Outra forma de assistir os índios idosos é incluí-los nos programas de bolsa-família ou aposentadoria.

Terra Indígena Inhakapetum

Próxima a São Miguel das M issões, a quinhentos quilômetros de Porto Alegre, a aldeia conta com 204 indígenas, uma das maiores da região Sul. Distante mais de trinta quilômetros de São Miguel, possui mata ciliar, rio, açude e vasta área para plantação.

A alimentação é composta por frutas silvestres, peixe, milho, batata-doce, além de produtos industrializados. A roça segue o modelo de subsistência. Um dos problemas obser vados pelo técnico da Funasa é quea época da colheita coincidecom o período de maior presença deturistas na região, que leva os jovens a deixar o campo para vender artesanato na cidade.

Há na aldeia um posto de saúde afastado do centro, respeitando a opy. Também há campo de futebol e escola juruá. As casas se mesclam entre as típicas dos M byá e as construídas pelo governo do estado. Possuem poço artesiano, água tratada e rio. Segundo a técnica da Funasa, o programa de saneamento e tratamento da água eliminou $80 \%$ do problema deverminose de diarréia, diminuindo a mortalidade infantil.

As doenças mais comuns relatadas pelo AISe técnicos da Funasa são problemas respiratórios, dermatológicos e dores de cabeça. Atuam deforma a esclarecer questões de saúde relacionadas a doenças sexualmente transmissíveis e acompanhar o desenvolvimento infantil. Com pelo menos três visitas por semana, em seis anos de trabalho, os técnicos da Funasa criaram vínculo consistente com a comunidade.

Em suas falas, afirmam que, quando os M byá são respeitados em suas tradições, inclusive em relação à opy e à língua, participam efetivamente dos tratamentos: "com o mínimo domínio do vocábulo Guarani [pelo técnico desaúde], eles setornaram mais confiantes". Exemplifica isso a coleta de escarro para o controle da tuberculose, à qual a comunidade aderiu sem resistência, e a diluição de medicamentos em chás, sel ecionados conforme a tradição, para promover sua aceitação. 0 convencimento torna-se efetivo pela explicação repetida e pela busca gradativa do envolvimento coletivo para conquistar a confiança. 
Com relação ao tratamento, respeitam a consulta à opy como primeira etapa para identificar se a doença é de índio ou não. Contudo, na fala da auxiliar de enfermagem da Funasa, sente-seo conflito cultural: "A genterespeita, masàsvezes, nos dói. $M$ uitas vezes, fico dividida entre a cultura e 0 agir. Tenho queagir. Há casos que são difíceis. 0 paciente está ruim etem queir antes para a casa dereza, opy. Só que, algumas vezes, o tempo é fundamental. Então, rezo para que o karaí possa identificar o mais rápido sea doença édeíndio ou debranco".

Há bom vínculo entre os técnicos da Funasa, Funai e os M byá. O AIS estava satisfeito por ser representante da comunidade e pelo seu vínculo com os técnicos da Funasa. Estes deixaram claro que 0 atendimento e 0 respeito à cultura sofrem com a rotati vidadee a tercei rização dos técnicos, que dificultam implementar programas oficiais de promoção à saúde. Umas das críticas mais graves é que o governo federal deslocou a assistência à saúde da Funai para a Funasa, sem considerar o quadro de pessoal. Também se referem à desval orização profissional, particularmentena contratação de terceirizados. Outra dificuldade para a assistência é a falta de transporte, pois dependem de veículo do Programa Saúde da Família (PSF).

\section{Aldeia Lomba do Pinheiro}

Localizada na periferia de Porto Alegre, a aldeia tem 65 pessoas. Sua localização vulnerabiliza o modo de vida $M$ byá em vários aspectos. $\mathrm{A}$ construção do posto de saúde não levou em conta a cosmologia Guarani, o que desgostou a comunidade. Além de ter sido construído de maneira inadequada, o posto não está funcionando, tornando preocupante também a situação de saúde do grupo.

A área física do aldeamento, encravada na periferia urbana e com todos os problemas de saneamento eorganização social costumeiramente observados nesses locais, não propicia a vida comunitária segundo a nhande rekó. Há uma pequena mata que atende de maneira limitada às necessidades. A organização espacial na aldeia também é precária devido ao pouco espaço para plantação. A pesar da construção de casas pelo governo, a maioria optou por construir a sua própria, alegando que a dos brancos não permitia práticas como o "fazer o foguinho".

A tensão cotidiana dessa situação é minimizada pela relação com agentes do M inistério Público e da Funai, pontes para o contato com a sociedade juruá. Durante as entrevistas, 0 indi- genista foi procurado para auxiliar sete mulhe resa resolverem problemas de identificação: certidão de nascimento, carteira de identidade, etc. A pesar da tensão constante, os M byá dizem que estão satisfeitos por estarem ali, ainda que enfrentando adversidades. A ocupação da área permite certa autonomia, identificada como liberdade e apontada nas entrevistas como um valor maior.

Entretanto, a proximidadedosjuruás dificulta manter tradições. Os mais velhos relatam que ainda conseguem influenciar os jovens na procura à opy, para identificar doenças e tratamentos; contudo, isto se torna cada vez mais difícil dada a influência da sociedade envolvente. Ainda assim, afirmam que a visão de saúde $M$ byá permanece relacionada à prática da oração, obediência a $\mathrm{N}$ handeru e aos conselhos dos karaí. Exemplos citados são casos de alcoolismo, latentes na comunidade, e outros transtornos de saúde, tratados (e curados) pelos karaí.

Os entrevistados salientaram que há uma barreira cultural entre os médicos e a visão de saúdee higiene dos $\mathrm{M}$ byá, principalmenteno trato das criançasena sua forma de educá-las quanto à higiene pessoal: " 0 médico quer saber mais que 0 índio. 0 médico vem e diz que as crianças Guarani não podem ficar peladas, pois podem pegar doença. Só que criança Guarani pode se acostumar com a terra e o tempo e isto não significa não gostar da criança enão cuidá-la".

Além do estranhamento dos médicos quanto aos valores e concepções da comunidade, foi apontada a inexistência de atendimento da Funasa. Quanto à assistência nos hospitais ou centros de saúde, mencionaram que, apesar de não se sentirem discriminados por serem indígenas, enfrentavam as mesmas dificuldades da população, como exemplifica o problema odontológico da comunidade. Em geral, as mulheres fazem os próprios partos.

Apesar de conseguirem manter seus rituais, sua cultura parece muito afetada pela local ização geográfica da aldeia ea forma como se estabelece o contato interétnico. Em uma das falas mais marcantes nessa localidade, identificou-se a descrença na "Terra sem M al", tida como concepção ideológica para evitar quea etnia reivindiqueterras. Os jovens se sentem duplamente excluídos, como se estivessem num "limbo" entre as duas culturas. Um deles, que cursou até a oitava série, disse que gostaria de continuar estudando e se formar em Direito, mas o programa que favore cia seus estudos terminou e ele não sabia se conseguiria prosseguir. Frente à fal ta de perspectivas, 
se dedicam à fabricação e venda de "bichinhos de madeira", que também é parte da tradição.

Com relação ao controle social, foi relatado que falta espaço institucional para efetivamente serem ouvidos na questão da saúde, particularmente na relação com a Funasa.

\section{Aldeia Araçaí}

Localizada em Chapecó (SC), com 120 habitantes, essa aldeia enfrenta grave problema fundiário, pois os M byá não possuem terras, morando de favor em área Kaingang. Tendo sido expulsos de suas terras de forma violenta durante a madrugada, continuam a enfrentar constantes mudanças, na maioria das vezes ocasionadas por medidas judiciais, impetradas por fazendeiros, para retirá-los de "suas" terras. Apesar de na área ocupada existir alguma mata nativa eo Rio Irani, a agricultura érudimentar, devido à instabilidade fundiária. Pela mesma razão, moram em casa de madeira ou barraco de lona plástica: "Ficamos na terras de N onoai, agora estamos aqui na terra Chimbangue, morando de favor. Tem atémato eágua, masnão éa nossa terra".

Sobre a visão de saúde, pode-se dizer que, de modo geral, associam-na à educação, religião, terra e alimentos. Segundo relatado, esses aspectos da vida não podem ser separados sob pena de trazer tristeza e doença: “N ão sepodeseparar saúde. É uma corrente. M uitas vezes vem a doença porque a gente perde uma coisa, pode ser a terra, o mato, então vem a tristeza ea doença". Outro entrevistado assegura: "M uita doença vem da comida. Q uando a gente come o milho, e as coisas da terra, não vem doença. As crianças sempretêm queir tratar na cidade. Acho queécomida errada, comemuita besteira, bala, doce. Adulto também come, maso verdadeiro Guarani deve comer somente o que a terra produz". Também remete a isso a fal a que relaciona saúde e espaço físico: "Os remédios a gente tira do mato, ou planta perto da casa. Sea gentenão tem mato e nem tem casa, aí fica difícil. M uitas vezes 0 branco não entende isso e nos dão os comprimidos, que também serve, mas o remédio melhor é a terra com tudo nela. Hoje a terra está nua, tiraram a roupa dela, não tem árvores. Isso traz doenças".

Quanto à relação com a Funasa e Funai, os relatos mostram que, em alguma medida, o estranhamento foi minimizado e estabelecido 0 diálogo: "Tem branco bom, que sabe como vivemos enão fala mal denós, vem da Funasa e Funai de Chapecó, traz remédio, nos visita, a gente fica um pouco feliz. Alguns entendem que temos nossa medicina e respeitam. Eu gosto quando chegam aqui sem pressa equando ficam conversando com a gente".

Foi ressaltado, em todas as entrevistas, a constante angústia decorrente do problema fundiário, da necessidade de terra boa para viver epara o roçado. Essa situação impede que se vivencie plenamente a nhande rekó, repercutindo na qualidade de vida e saúde da comunidade, tanto individual quanto coletivamente.

\section{Discussão}

O Decreto Lei n 3.156/99 dispõe sobre as condições para prestação de assistência à saúde dos povos indígenas no âmbito do Sistema Ú nico de Saúde (SUS), reiterando o cumprimento da Lei n 8.080/90, cujos objetivos são a universalidade, integral idade e equanimidade dos serviços. Atualmente, a assistênciaé prestada pela Funasa, que aloca profissionais para trabalhar na assistência básica nas aldeias, sendo responsável também por assegurar a prestação nos demais níveis, mediante o encaminhamento a hospitais e outras unidades de saúde.

Dentre os nove incisos do parágrafo $2^{\circ}$ daquele decreto, voltados a regulamentar aspectos específicos da assistência básica à saúde indígena, destacam-se dois nessa análise, que se referem à dimensão social das comunidades e apontam a importância de reconhecer suas especificidades culturais e contribuir para seu equilíbrio ${ }^{5}$. Quanto a essas determinações de cunho social, é importante apontar a grande diferença no que concerne à localização e recursos naturais disponíveisentreas aldeias visitadas, queparecem guardar estreita relação tanto com a percepção, quanto com as condições de saúde da comunidadeem cada uma delas. As entrevistas permitiram identificar que, mesmo em contato contínuo com os juruá, nas aldeias em que os $M$ byá conseguem viver de acordo com o nhande rekó, Pacheca, Inhakapetum e, atécerto ponto Araçaí, tal representação espelha a noção de qualidade de vida e funde-se à ideia de saúde.

$N$ essas três comunidades, a presença das matas e da água, a possibilidade de cultivar a terra no plantio do avati e das espécies destinadas a tratamento, assim como a manutenção das dinâmicas sociais tradicionais, como a opy, o respeito aos karaí para identificação das doenças ea cura, bem como a guata para o aprimoramento espiritual, podem ser relacionados àquilo que a sociedade juruá convencionou chamar de promoção à saúde, como prevêo artigo 196 da Cons- 
tituição ${ }^{6}$. Segundo a observação e as entrevistas, a promoção à saúde por meio da garantia às condições objetivas para a manutenção do nhande rekó tende não somente a aumentar a autonomia e emancipação das comunidades, mas também a diminuir a necessidade de assistência dos juruá para recuperar a saúde. Como a promoção da saúde pode ser relacionada a essas práticas autóctones, pode-se inferir a importância de permitir efomentar o modo de ser Guarani para garantir a saúdee a qualidade de vida das comunidades, como previsto no Decreto $\mathrm{n}^{\circ} 3.156 / 99^{7}$.

Em contrapartida, em Lomba do Pinheiro, a falta de espaço e recursos para viver de acordo com o nhande rekó faz com que a representação da "Terra sem M al" comece a ser vista como ideologia de dominação. Essa ruptura na dimensão simbólica parece ser consequência lógica da impossibilidade de vivenciar o cotidiano de acordo com a tradição, já que a cosmogonia M byá e a vida cotidiana do grupo não são percebidas como dimensões distintas ${ }^{1-3}$, como acontece na sociedade dos brancos, mas constituem um único todo que orienta as práticas sociais e o comportamento. A situação observada nessa aldeia é preocupante, pois embora se admita que a cultura não é estática e sim um processo social em constante transformação ${ }^{4}$, tal ruptura com os valores e crenças tradicionais pode vulnerabilizar ainda mais a comunidade caso a luta pela terra, implicada nesses novos valores, não alcance o resultado esperado. Nesse caso, a equidade para a promoção da saúde é inviável.

Se viver de acordo com o modo de ser Guarani parece influenciar diretamente as condições de saúde, é inegável que a assistência também produz impacto. Nas aldeias onde a Funasa está presente, garantindo em maior ou menor grau o acesso aos serviços, constata-se que os problemas de saúde tendem a ser resolvidos tecnicamente, diminuindo a ocorrência de quadros crônicos. Foi observado nos depoimentos das aldeias de Camacuã, Inhakapetum e Araçaí que quando há respeito às diferenças, é possível construir boa relação entre as equipes da Funasa, Funai e os M byá. A pesar da Funai não mais atuar com a saúde indígena, na prática, colabora com a Funasa, facilitando a inter-relação entre os técnicos de saúde e as comunidades.

A efetividade da assistência prestada por essas instituições relaciona-se diretamente com a cultura nativa, aproximando-se do princípio da beneficência proposto por Engelhardt: "Faça aos outros o bem deles"8. Especialmente em relação à Funasa, o fato do técnico falar a língua Guara- ni, bem como respeitar suas crenças e rituais, são condições essenciais para o sucesso na relação terapêutica. N ota-se, entretanto, que as iniciativas da Funasa para capacitar seus técnicos para o contato ainda não são suficientes, seja no conhecimento das peculiaridades culturais, da língua ou mesmo quanto ao respeito à diversidade que precisa pautar as relações interétnicas. Como consequência, as comunidades são vistas de forma assimétrica, pelo olhar da ideologia juruá, queintensifica o estranhamento moral. Esseolhar assimétrico, por parte da sociedadenão indígena, pode ser observado na última coluna do Quadro 1 , onde se encontra a comparação da visão de mundo, tanto da etnia Guarani M byá, como dos não indígenas (Juruá).

O conceito de estranhos morais, de Engelhardt, diz respeito às diferenças reais entre as visões morais de pessoas ou grupos, às quais podem impedir (e frequentemente impedem) que os participantes de uma controvérsia cheguem à resolução do conflito por meio do debate sustentado por sadios argumentos racionais ou pelo re curso a uma autoridade moral comumente reconhecida, como menciona Engelhardt ${ }^{8}$, uma vez que não partilham de perspectiva cultural ou moral a partir da qual possa ser estabelecido diálogo. Pode-se delinear a complexidade do problema entre a sociedade juruá e os M byá, na comparação das categorias que sistematizam suas concepções de saúde e modo de vida.

Apesar de não contarem com efetivo suporte institucional para desempenhar suas atividades nas comunidades, as necessidades objetivas da comunicação com os indígenas motiva os técnicos da Funasa a aprenderem sua língua e costumes. Este compromisso espontâneo tende a favorecer o diálogo e se traduz em bioética, como respeito, tolerância e compreensão das diferenças morais e culturais. Porém, mesmo nesses casos, em que buscam superar a lacuna do estranhamento cultural emoral, a dificuldade no contato interétnico subjaz, já que a assistência é baseada na valorização da medicina e da cultura brancas e desqualificação das práticas e concepções nativas. Isso tende a agravar a assimetria, perpetuar o estranhamento e o choque cultural, dificultando ou inviabilizando a adesão ao tratamento e criando obstáculos ou impedindo que as lideranças sejam tomadas como interlocutores legítimos de controle social na definição de políticas públicas.

A assimetria faz com que a tolerância, estratégia apontada por Engelhardt ${ }^{8}$ para superar 0 estranhamento moral, deixe deproduzir o resul- 
tado esperado: o consentimento. Quando uns têm poder para impor sua perspectiva e a outros falta poder para recusá-la, a tolerância deixa de ser instrumento para o diálogo e passa a refletir dominação e subserviência9.

Tal é o caso dos povos indígenas brasileiros que, segundo o Estatuto do Índio (Lei no 6.001/ 73) ${ }^{10}$, não têm autonomia decisória, sen do tutelados pelo Estado. Se tal condição foi imposta sob o argumento da proteção, é importante ressaltar que não deixa de limitar a cidadania dos indivíduos e a autonomia dos grupos, diminuindo sua autodeterminação como povo: sua capacidade de definir os rumos de sua própria história. Exemplifica isso o fato de nenhuma das 180 línguas indígenas serem reconhecidas como idioma oficial brasileiro. A falta de autonomia e a assimetria em relação à sociedadee cultura juruá parecem se acentuar quando as aldeias localizam-se em áreas urbanas, circunstância na qual os $M$ byá se sentem duplamente excluídos, por serem indígenase por serem tratados como pobres.

Os entrevistados apontam a posse da terra como um avanço na conquista das liberdades fundamentais, facultadas aos demais cidadãos do país. Relatam que as comunidades que possuem tal garantia têm um mínimo de autonomia, inclusive para decidir pela adesão ou não aos programas governamentais, seja em relação à moradia, educação ou saúde. De modo geral, no entanto, a percepção dessa autonomia e participação nos mecanismos de controle social é bastante restrita e que, como grupo, ainda estão longe de integrar as instâncias deliberativas do poder, para fazer valer suas escolhas na definição dos programas a eles destinados, inclusive os de saúde. Garnelo et al. ${ }^{11,12}$ apontam que controle social é visto pel os grupos indígenas como atividade política, exercida junto às instituições gestoras das políticas sanitárias, que podem facultar espaços de poder não apenas na luta pelo direito à saúde, mas também no contexto geral das relações interétnicas.

A legitimidadedo poder político daliderança é dada pela filiação ao grupo e o exercício de solidariedade é direcionado pelas regras; características da forma de organização com importanter reflexo no desenvolvimento do controlesocial. Mas, ouvir, entender edebater, peculiares ao ethos M byá, não são suficientes para garantir suas de mandas frenteà sociedadejuruá. Como parte da resistência constantepela integridadedeseu ethos, os M byá buscam assegurar o exercício do controle social sobre as políticas públicas que lhes asseguram a assistência, participando dos fóruns de discussões oficiais, como a Conferência dos Povos Indígenas.

Para minimizar a assimetria econômica das comunidades, políticas públicas assistencialistas acabam por colaborar, direta ou indiretamente, na assistência, com três tipos de ações: a cesta básica, a aposentadoria e a bolsa-família. A respeito, $\mathrm{Witt}^{5}$ assevera que essas ações propiciam, de forma positiva, a permanência nas aldeias, diminuem a mendicância, melhoram aspectos de saúde; porém, geram acomodamento, dependência e exploração, principalmente dosidosos. Ressalte-se que, ao longo da história indígena, 0 assistencialismo foi crucial para a sobrevivência de al gumas etnias, por isso o assunto necessita maior reflexão, que não cabe aqui. 0 assistencialismo deveser visto sempre como etapa passageira, para impulsionar a efetiva mudança da dependência para a corresponsabilidade.

Quadro 1. Comparação da visão de mundo.

\begin{tabular}{|l|l|l|}
\hline \multicolumn{1}{|c|}{ Categorias } & \multicolumn{1}{c|}{ Paradigma de saúde M byá } & \multicolumn{1}{c|}{ Paradigma de saúde juruá } \\
\hline M odo de produção & Produção em pequena escala/Subsistência & Produção em grande escala/consumo \\
\hline Característica da dinâmica social & Deslocamento/movimento & Permanência/estabilidade \\
\hline Parâmetro de sociabilidade & Solidariedade & Competição \\
\hline Característica da propriedade & Coletiva & Privada \\
\hline Parâmetro relacional & Grupo & Indivíduo \\
\hline Característica da doença & Psicossomática e espiritual & Biológica \\
\hline Percepção da causalidade & Sociedade doente & Indivíduo doente \\
\hline Forma de tratamento & Xamânica, fitoterápica, alimentar & Alopática \\
\hline Ideia de saúde & Espiritualidade/corpo (integral) & Saúde biomedicina (fragmentada) \\
\hline
\end{tabular}


Valorizar o nhandé rekó e a liberdade, valor constituinte do ethos dessa etnia, é essencial para que os "vulnerados"13 possam se tornar sujeitos autônomos, interagindo em condição de igualdade com os juruá: "quando falo de felicidade e tranquilidadenão estou dizendo de afastar do branco, mas deixar índio tranquilo, não chegar mandando o que tem que ser feito. Aqui a família está tranquila. Não queremos compromisso antes de avaliar o queémelhor para a aldeia. Qual o projeto que vai aplicar? As mulheres Guarani precisam de tranquilidade. Elas já sabem plantar no tempo certo e com a natureza. Não precisa chegar ninguém e dizer como plantar. Quanto mais tranquiIo, mais qui eto, e isso é a felicidade".

\section{Considerações finais}

Esta análise apontou alguns aspectos da assistência à saúde aos $M$ byá que precisam ser meIhorados para garantir efetividade na atenção: (1) melhoria no gerenciamento e operacionalização das políticas públicas; (2) simetria no contato interétnico e (3) justiça na distribuição dos recursos para as comunidades indígenas, tal como preconiza a bioética.

Quanto ao primeiro ponto, destacam-se: melhorar a infraestrutura, inclusive de comunicação e transporte; diminuir a burocracia institucional, pulverizada em onze instâncias federais (ministérios) e várias outras nos governos locais (estaduais e municipais); aprofundar o relacionamento interinstitucional e melhorar a integração entre os órgãos governamentais que assistem diretamente as comunidades (Funasa e Funai). Além destas medidas pontuais, faz-se necessário que a questão fundiária seja considerada a partir da visão do próprio grupo, tomada como um dos pilares para a promoção de sua saúde.

Em relação ao segundo aspecto, é preciso modificar a visão tecnicista que pauta o modelo de assistência à saúde nas aldeias, para fomentar vínculos estreitos com as comunidades aprimorar a qualidade da capacitação dos profissionais quelidam com os $\mathrm{M}$ byá, particularmente quanto à cultura emoralidade do grupo; valorizar os profissionais, diminuindo a rotatividade e a terceirização, e ampliar a inserção dos AIS bem como dos representantes das aldeias (chefes), na definição das prioridades em políticas públicas. 0 respeito no contato interétnico poderesultar em processos permanentes de reconstrução de saberes, tanto para os M byá quanto para a sociedade envolvente, promovendo a saúde por políticas ambientais e de saneamento adequadas e efetivas.

No que diz respei to à justiça, a pesquisa mostrou que se as racionalidades ocidental e indíge na baseiam-se em sistemas de conhecimento e paradigmas distintos; estes podem interagir e, talvez, até se complementar, como observado em Pacheca e Inhakapetum. Quando há respeito à alteridade, o contato interétnico é menos assimétrico. Assim, os grupos minoritários, como os M byá, tornam sua cultura visível, respeitada e legítima para não índios. Essa valorização da diferença e da diversidade é essencial para a digna inserção dos M byá na sociedade brasileira, de acordo com o seu verdadeiro modo de ser. 


\section{Colaboradores}

AA Von Held e SM NB Sá trabal haram igualmente em todas as fases do artigo, desde a coleta de dados no trabalho de campo até a elaboração e redação final do artigo. DOS Porto participou do delineamento da metodologia, análise dos dados, concepção teórica, orientação, revisão e redação final do artigo. M SC Lopes participou da elaboração do artigo nas fases de concepção, delineamento e interpretação dos dados coletados.

\section{Agradecimentos}

Aos indígenas da etnia Guarani M byá das comunidades visitadas e as Unidades Regionais da FU NAI no Rio Grande do Sul e Santa Catarina.

\section{Referências}

1. Ladeira MI. Guarani M byá. Organização social, política e religiosa. Enciclopédia dos povos indígenas no Brasil. Instituto Sócio Ambiental. [site da Internet] [acessado 2008 mar 10] Disponível em: http:// www.socioambiental.org/pib/epi/guaranimbya/soc. shtm

2. Cicarrone C. Drama e sensibilidade. Migração, xamanismo e mulheres guarani M by'á. Revista das Índias 2004; LXIV(230):81-96.

3. Guimarães SM F. A marcha cerimonial guaranimbyá: anuário antropológico. Rio de Janeiro: Tempo Brasileiro; 2004. p. 151-192.

4. Almeida, RT. Breve comentário sobre a saúde e relações de contato: os guarani brasileiros. Saúde em Debate 1988; (n.esp):28-32.

5. Witt F. Depoimentos e comentários do indigenista da Funai. 2007.

6. Brasil. Constituição da República Federativa do Brasil. Brasília: Senado Federal; 1988. p. 133.

7. Brasil. Decreto $n^{\circ} 3.156$, de 27 de agosto de 1999. Dispõe sobre as condições para a prestação de assistência à saúde dos povos indígenas e dá outras providências. Diário Oficial da União 1999; 28 ago.

8. Engelhardt Jr. HT. As bases da bioética. In: Engelhardt Jr. HT. Fundamentos da bioética. São Paulo: Loyola; 1998. p. 126.

9. Garrafa V, Porto D. Bioética, poder e injustiça. São Paulo: Loyola; 2003.

10. Brasil. Lei $n^{\circ}$ 6.001, de 19 de dezembro de 1973. Dispõe sobre o Estatuto do Índio. Diário Oficial da União 1973; 21 dez.

11. Garnelo L, Sampaio S. Bases sócio-culturais do controle social em saúde indígena: problemas e questões na região norte do Brasil. Cad Saude Publica 2003; 19(1):311-317.

12. Garnelo L, Macedo G, Brandão LC. Os povos indíge nas e a construção de política de saúde no Brasil. Brasília: Organização Pan-Americana de Saúde; 2003.

13. Schramm FR. A saúde é um direito ou um dever? U ma autocrítica da saúde pública. Revista Brasileira de Bioética 2006; 2(2):187-200.

Artigo apresentado em 20/05/2008

Aprovado em 28/11/2008

Versão final apresentada em 26/12/2008 